\title{
Femur başı epifiz kayması olan hastalara güncel tanı ve tedavi yaklaşımı
}

\section{Current diagnostic and therapeutic approach to patients with slipped capital femoral epiphysis}

\author{
Mehmet Ali Talmaç, Hasan Basri Sezer \\ Şişli Hamidiye Etfal Eğitim ve Araştırma Hastanesi, Ortopedi ve Travmatoloji Kliniği, İstanbul
}

Femur başı epifiz kayması (FBEK), ergenlik çağındaki çocuklarda büyümenin hızlı evresinde femur üst uç epifizindeki yumuşama ve fazla kiloya bağlı artmış makaslama kuvvetleri nedeniyle, femur üst uç epifizi ile femur boynu arasındaki ilişkinin bozulmasıdır. Bu hastalık 100 000'de 10,8 oranında görülür. Tipik olarak kasık, uyluk ya da dizlerinde ağrı ve yürümelerinde aksama ile başvuran kilolu erkek adolesan hastaları kapsar. Etiyolojisi genellikle idiyopatiktir; ancak, bazen endokrin hastalıklar, böbrek hastalıkları veya radyoterapi zemininde de gelişebilir. Klinik muayenede hastaların kalça eklem hareketleri kısıtlanmış olup alt ekstremitelerini eksternal rotasyon ve fleksiyonda tutma eğilimleri vardır. Hastaların yaklaşık olarak yarısında bilateral tutulum vardır. Bu durumda aynı seansta profilaktik in situ vidalama konusu tartışmalı olmaktadır. FBEK, geleneksel olarak iki metod ile sınıflandırılır: 1) zamana dayalı olarak, akut, kronik üzerine akut, kronik; 2) stabiliteye göre, stabil ve instabil. Eğer tedavide başarı sağlanamazsa, FBEK'li hastalarda avasküler nekroz, kondroliz ve femoroasetabular sıkışma sendromu gibi komplikasyonların sonucunda erken yaşta eklem dejenerasyonu gelişir. Bu yazıda hastalığın etiyopatolojisi, tanısı, takibi ve güncel tedavisi konularında farkındalık arttırılmaya çalışılmıştır.

Anahtar sözcükler: femur başı; kayma, epifiz; femur başı nekrozu
Slipped capital femoral epiphysis (SCFE) is defined as the disruption of the relationship between the proximal femoral epiphysis and the femoral neck because of softening of the proximal femoral physis and increased shear forces due to rapid growth and increased body weight during puberty. It has a prevalence of 10.8 in 100000 . The usual presentation of the patients is overweighted male adolescent with complaints of groin, thigh or knee pain and a limp. It is mostly idiopathic, however the patient might be affected by endocrine, nephrological conditions or it may be due to radiotherapy. The physical examination reveals limitation of hip motion, and patients have tendency to position their lower extremity externally rotated and flexed. Almost half of the patients are affected bilaterally. Thus, there rises a debate about prophylactic in situ pinning. SCFE is classically classified in two categories: 1) according to the time of onset as acute, acute-on-chronic and chronic, and 2) according to the stability as stabile or instabile. In case of failed treatment, SCFE has devastating results like avascular necrosis, chondrolysis, and femoroacetabular impingement resulting in early arthrosis. In this paper we attempt to increase the awareness on the ethiopathology, diagnosis, progression and current treatment modalities of SCFE.

Key words: femoral head; dislocation, epiphysis; femur head necrosis
F emur başı epifiz kayması (FBEK) adolesan çağda en sık görülen kalça patolojisidir. ${ }^{[1]}$ Femur başı epifizinin proksimal femur metafizinden ayrışıp kaymasıdır. Hızlı büyüme çağındaki obez adolesan çocuklarda fazla görülmesi, zayıf femur başı epizinin fazla yük taşımasına bağlanır. Femur başı epifizinin asetabulum ile ilişkisi bozulmaz ve femur boynu anterosuperiora deplase olup epifiz nispeten posteriora deplase olmuş gibi görünür. Valgustaki FBEK olgularında femur boynu postero-inferiora deplase olabilir. ${ }^{[2]}$
FBEK ilk olarak 1572 de Pare (Ambrose Pare, 15101590) tarafindan femur başı epifiz kayması olarak tanımlanmış ${ }^{[3]}$ ve Boyd (John Boyd Colquhoun, 18991974) ilk olarak 1909'da femur başı epifizini pin ile stabilize etmiş̧ir. ${ }^{[4]}$

\section{EPIDEMIYOLOJi}

FBEK sıklığı, ırk, cinsiyet ve coğrafik bölgeye göre değişmekle birlikte, ortalama 100000 'de 2 oranında

- İletişim adresi: Uzm. Dr. Mehmet Ali Talmaç, Atakent Mah. İstanbul Cad. Bosphorus Sinpaş City Erguvan Evleri, No: 6B/28 Halkalı, Küçükçekmece, İstanbul Tel: 0555 - 5529329 e-posta: drtalmac2@gmail.com

- Geliş tarihi: 3 Eylül $2014 \quad$ Kabul tarihi: 3 Eylül 2014 
görülür. Sıklık, ırk ve coğrafik bölgeye göre 100 000'de 1-7 arası değişir. Hastaların \%51-77'si obez olup, \%50'si 90 persantilin üzerindeki ağırlıklara sahiptir. ${ }^{[5,6]}$ FBEK daha çok puberte çağındaki çocuklarda görülür. Loder ve arkadaşlarının yaptığı gözlemsel 1600 olguluk çalışmada; kızlarda $12 \pm 1,5$, erkeklerde $13 \pm 1,7$ yaşlarında daha sık görüldüğü tespit edilmiştir. ${ }^{[5]}$ Hagglund ve arkadaşlarına göre, FBEK erkeklerde kızlardan iki kat fazla, sol kalça sağ kalçaya göre ise üç kat daha fazla tutulum gösterir. ${ }^{[7]}$ FBEK \%18-50 arası değişik sıklıkta iki taraflı tutulum sergiler. ${ }^{[8]}$ Nispeten küçük yaşlarda ve endokrin hastalığı olanlarda iki taraflı tutulum daha fazla olur. Riad ve arkadaşlarına göre, 10 yaşından küçük kız çocuk ve 12 yaşından küçük erkek çocuklarda FBEK gelişmişse, karşı tarafı da aynı seansta tedavi etmek gerekir. ${ }^{[9]}$

\section{SINIFLAMA}

\section{Semptomatik}

Semptomların başlama zamanına göre akut, kronik üzerine akut ve kronik olarak sınıflandırılır.

íki-üç haftadan az prodromal semptom sonrası gelişen kaymalar akut olarak isimlendirilir. Genellikle ani gelişen ve dramatik bir tabloyla başvuran hastada femur üst ucunda Tip 1 epifizyolize neden olacak kadar büyük olmayan bir travmayı takiben ortaya çıkar ve radyografilerde remodelasyona ait bulgular saptanamaz. Bu durum Tip 1 epifizyolizden ayırt edilmelidir. Hastaların, başlangıçta bir miktar kasık, uyluk veya diz ağrısı mevcuttur ve bunlar, hafif bir burkulma veya düşmeyi takip eder. Akut FBEK'de avasküler nekroz (AVN) riski literatürde \%17-47 gibi yüksek bir oranda bildirilmiştir. ${ }^{[10]}$

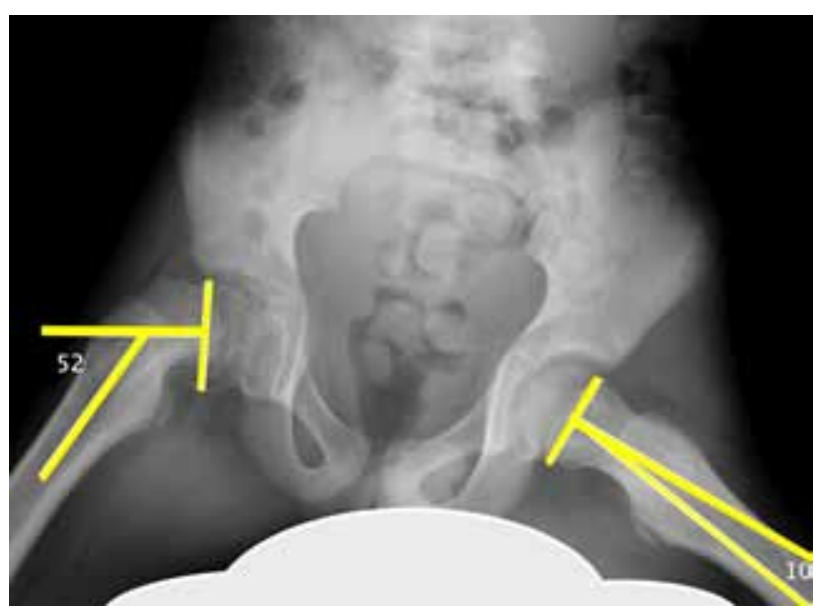

Şekil 1. "Frog leg" lateral grafide kayma açısının ölçümü.
Kronik FBEK en sık görülen formdur. Birkaç ayı bulan hafif şiddetli bir prodromal kasık-uyluk ağrısı ve aksama dönemi mevcuttur. Loder'in bir çalışmasında 1630 çocuğun 1993 kalçası incelenmiş ve kaymaların \%85 oranında kronik olduğu saptanmıştır. ${ }^{[11]}$ Hastaların grafilerinde femoral epifizin değişen miktarlarda posteriora kayması ve bu düzlemde bir remodelasyon mevcuttur. Bu durum Müller tarafindan femur boynunun eğilmesi olarak tarif edilmiştir. ${ }^{12]}$

Kronik üzeri akut FBEK hastalarında üç haftadan fazla süren bir prodromal dönemi takip eden akut ağrı mevcuttur. Radyografilerde boyunda remodelasyon ve bunun ilerisine devam eden bir kayma görülür.

\section{Fonksiyonel}

Başvuru esnasında basıp basamamalarına göre Loder ve arkadaşları tarafından hastalar stabil ve instabil olarak sınıflandırılmışlardır. İnstabil kaymalar koltuk değneği ile bile yük veremez. Loder ve arkadaşları instabil kaymalarda daha fazla AVN olduğunu bildirmişlerdir. ${ }^{[11]}$

\section{Morfolojik}

Kayma miktarına göre hastalar sınıflandırılır. Sauthwick femur baş-boyun açısını ölçerek $30^{\circ}$ 'nin altında kaymaları hafif, $30-60^{\circ}$ arasında kaymaları orta ve $60^{\circ}$ üzerinde kaymaları ağır olarak sınıflamıştır. Sauthwick bu açıların AP grafilerde $145^{\circ}$ ve lateral grafilerde $10^{\circ}$ olduğunu bildirmiştir (Şekil 1, 2)..$^{[13]}$

\section{ETIYOPATOGENEZ}

FBEK'de nedeni tam olarak bilinmemesine rağmen biyomekanik, hormonal ve genetik nedenler femur

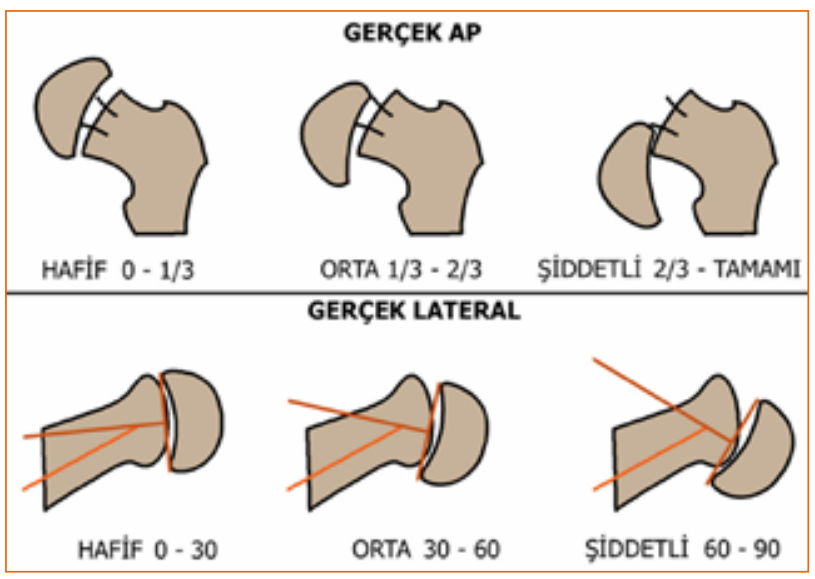

Şekil 2. Southwick'e göre FBEK'de kayma miktarı ve açısına göre sınıflama. 
başı epifizini zayıflatıp patolojiyi oluşturduğu düşünülmektedir. Mekanik faktörler akut ve şiddetli FBEK olgularına neden olurken, hormonal faktörler eklem şeklini ve eklem içi dejeratif değişikliklere neden olup kronik form olarak karşımıza çıkmaktadır.

\section{MEKANIK FAKTÖRLER}

1- Perikondrial halkanın ince olması:

Epifizin kıkırdak kısmını çepeçevre kemiğe bağlayan ve yüklenmelerde mekanik destek sağlayan Tip II kollajenden oluşan bir yapıdır.

2- Femur boynunun retroversiyonu:

Retroversiyon artıkça femur proksimaline AP planda daha fazla kuwet yüklenmektedir.

3- Adolesanlarda femur proksimal epifizinin inklinasyon açısının değişmesi:

Proksimal femur epifizinin oblik eğimi arttıkça FBEK gelişimine yol açtığı düşünülmektedir. ${ }^{[14]}$

\section{ENDOKRIN NEDENLER}

Tiroid, seks hormonları ve büyüme hormonu patolojileri olan obez, hipogonadal erkek hastalarda bilateral tutulum daha fazla görülür. ${ }^{[15,16]}$ Hastanın ağırlığı fazla ve yaşı 10 'dan az ya da 16'dan fazla ise daha fazla biyokimyasal test yapmak gerekir ve bu hastalarda atipik FBEK görülür. ${ }^{[17]}$ FBEK daha çok hipotiroidizmde görülmekle beraber büyüme hormonu eksikliği ve böbrek yetmezliğine bağlı hipertiroidizmde de görülür. Hormonal bozukluğa bağlı gelişen FBEK \%61 bilateral tutulum ile karşımıza çıkar. Kronik böbrek yetmezliğine sekoner gelişen hiperparatiroidizmli hastaların \%95'inde bilateral tutulum mevcuttur. Eğer kronik böbrek yetmezliği tedavi edilmeyip cerrahi olarak FBEK pin ile tespit edilirse hastaların \%57'sinde femur başı epifiz kayması devam eder. Dolayısıyla bu hastalarda kemik matüritesinin tamamlanmasını beklemek gerektiği düşünülmektedir. ${ }^{[18]}$

\section{PATOLOJi}

FBEK'de epifiz posteriora kaydığından femur boynu periostu anteroinferiora yerdeğiştirir ve zamanla femur boynunun posterior kısmı kallus dokusu ile dolar. Femur boynu anterosuperior bölgesi remodele olamayıp çıkıntı oluşur ve sıkışmaya neden olur. ${ }^{[19]}$ Kayma öncesi makroskopik olarak sinoviyal membran ödemli, kapsül ve periost genişlemiş durumdadır. Fakat mikroskopik olarak epifizin dinlenme zonu normal olup, proliferatif ve hipertrofik zon nispeten daha kalın görülmüştür. ${ }^{[20,21]}$ Proliferatif ve hipetrofik zonda kıkırdak hücre sayısı azalıp matriks dokusu artmış olarak saptanmıştır. Kaymış femur başı epifizi elektromikroskopik olarak incelendiğinde; hipertrofik ve proliferatif zonda kollajen fibrilleri az, değişken boyutta ve düzensiz organize olup en önemli değişiklik hipertrofik zondaki kondrositlerin dejenerasyonu ya da ölümü olarak görülür. ${ }^{[22]}$

\section{KLINIK ÖZELLIKLER}

Semptom ve muayene bulgaları, FBEK'in kronik, kronik üzerine akut ve akut olması yada kaymanın stabil ya da instabil olup olmaması ve gelişen deformitenin büyüklüğü, AVN ve kondroliz gibi komplikasyonların olmasına göre değişir. Yaklaşık \%20 civarında iki taraflı tutulum olduğundan hastayı klinik ve radyolojik olarak çok iyi değerlendirmek gerekir.

\section{Stabil femur başı epifiz kayması}

Stabil kronik FBEK'de kasık, uyluk ön yüz ve dizde ağrı şikayeti ile başvurulur. Bu hastalarda özellikle distal uyluk ön yüzü ve dizde ağrı olduğundan tanı gecikmesine neden olmaktadır. Kalçasında ağrı olmadan diz ve uyluk distal önyüzünde ağrı ile başvuran adolesan hastalarda mutlaka kalçayı da klinik ve radyolojik olarak değerlendirmek gerekir. Ağrı, tipik olarak belirsiz olup aralıklı ya da devamlı olabilir ve bununla beraber fiziksel aktivitelerle de artabilir. Ağrı haftalar ya da aylardır vardır. Hastalar antaljik aksama şeklinde yürürler ve alt ektremiteyi eksternal rotasyonda tutarlar. $\mathrm{Bu}$ hastaların muayeneleri sırasında zorlayıcı hareketlerden kaçınmak gerekir aksi takdirde akut FBEK'e neden olunabilir. Bu hastaların kalça hareketlerinde fleksiyon, internal rotasyon ve abduksiyon kısıtlığı vardır. Kalçalarını ekstansiyon, adduksiyon ve eksternal rotasyonda tutma eğilimindedirler. Stabil FBEK'de muayene sırasında internal rotasyon kısıtlılığı olması ve internal rotasyon kısıtlılığı aşılmasında ağrı oluşması anahtar bir bulgudur. Fleksiyon kontraktürü femur başı kondrolizi açısından uyarıcı olmalıdır. Kronik FBEK'li hastaların tipik özellikleri erkek obez ve hipogonadal olmalarıdır. ${ }^{[23,24]}$

\section{Stabil olmayan akut ya da kronik üzerine akut femur başı epifiz kayması}

Hastalar stabil olmayan akut ya da kronik üzerine akut FBEK'de basit bir düşme yada burkulma sonrası kalçada ani başlayan, şiddetli ve kırık gibi bir ağrı şikayeti ile başvururlar. Semptomlar çok şiddetli olup hastalar basamazlar. Doktorlar bazı talihsiz nedenlerden dolayı tanı koymada gecikebilir ve hasta basmaya devam ederse avsküler nekroz ve kondroliz riski fazlasıyla artmış olur. Hastalar genellikle alt ekstremilerini uzatıp eksternal rotasyon pozisyonunda tutarlar. 
Hafif kısalık görülebilmekle beraber hareketle şiddetli ağrı olur.

\section{RADYOLOJIK BULGULAR}

\section{Röntgenogram}

Genellikle FBEK’i AP ve kurbağa bacağı röntgenler ile değerlendirmek yeterlidir. Erken röntgenografik bulgular epifizde genişleme ve metafizyel düzensizliklerdir. Bu bulgulara kayma öncesi belirtiler denilmektedir. ${ }^{[25,26]}$ Erken evre hafif kaymalarda, AP planda posterior deplasman bazen gözden kaçabilir. Normal kalçada AP grafide femur boynu superiorundan teğet çizilen çizgi (Klein çizgisi) femur başı epifizinin lateralinin bir kısmını keser (Şekil 3). ${ }^{[27]}$ Femur başı posteriora deplase olursa Klein çizgisi femur başı epifizinin çok az bir kısmını keser, tam kaymalarda ise epifizi kesmeyebilir (Trethowan bulgusu).

\section{Bilgisayarlı tomografi}

FBEK'de bilgisayarlı tomografi genellikle kullanılmaz. ${ }^{28]}$ Daha çok femur proksimal versiyonu (anteretro), obez ve sert kalçalarda postoperatif olarak uygulanan vidanın eklem penetrasyonunu değerlendirmek ve kayma sonrası gelişen deformiteleri tanımlamak için kullanılır.

\section{Teknesyum 99 ile kemik sintigrafisi}

FBEK'de femur başı epifizinde ve femur başının kondroliz olan bölgesinde tutulum artarken, AVN bölgesinde sintigrafik tutulum azalır.

\section{Ultrasonografi}

Ultrasonografi ile femur başı epifiz kayması değerlendirilebilir. Birçok araştırmacı ultrasonografide kalça ekleminde eklem içi effüzyon ve femur boynu ile epifiz arasında basamak oluşmasının erken kayma belirtisi olduğunu belirtmektedir. ${ }^{[29]}$

\section{Manyetik rezonans (MR) görüntüleme}

$M R$, femur başı epifiz kaymasını erken dönemde yakalanmasına rağmen; röntgen, bilgisayarlı tomografi ya da ultrasonografi gibi daha ucuz yöntemlerle de aynı patoloji yakalanabilir. ${ }^{[30]}$ Eğer radyolojik olarak normal ise hastanın şikayetleri devam ediyor ve klinik muayenede FBEK açısından şüphemiz varsa MR ile epifizde genişleme ve düzensizlik saptanması erken evre FBEK'i gösterir.

\section{TEDAVi}

Tedavideki temel amaç epifiz kayma sürecini durdurmak ve olası komplikasyonları önlemektir. Stabil FBEK şüphesi varsa ve radyolojik olarak tanısı konulmuşsa, hastaya tekerlekli sandalye önerilir ve koltuk değneği ile basması engellenir. Eğer hastanın instabil FBEK'i varsa kesin tedavisi düzenlenene kadar, cilt traksiyonu ile immobilize edilip analjezisi sağlanır. Kesin tedavi seçenekleri arasında perkütan in situ internal tespit (Kirchner teli ya da kanüllü vida), kemik grefti ile epifizyodez ya da osteotomi ve alçı uygulaması vardır.

\section{Stabil FBEK tedavisi}

Stabil FBEK'de perkütan in situ vidalama, femur başı epifizi ile femur boynunu stabil tespit sağlayan bir ya da iki adet kanüle vida ile tespit etmektir (Şekil 4). Bu cerrahi teknikte traksiyon masası kullanılması radyolojik olarak düzgün AP ve frog lateral görüntü elde etmemizi sağlamaktadır. Vida femur boynu anteriorundan epifizi tam ortalayacak şekilde

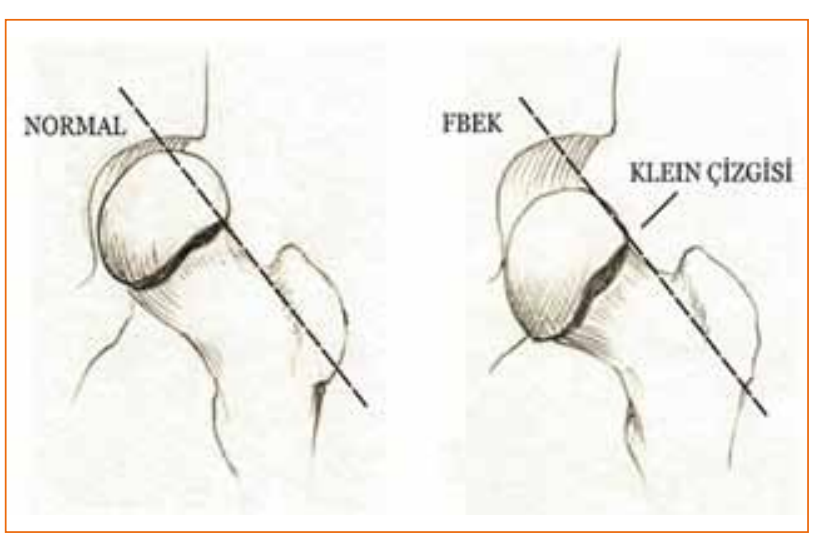

Şekil 3. a, b. Klein çizgisi.

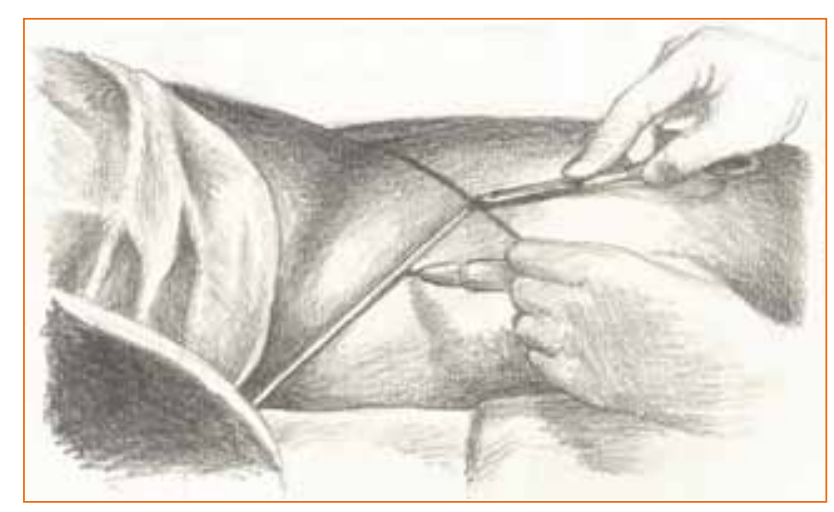

Şekil 4. Traksiyon masasında perkütan vidalama öncesi insizyona hazırlık. 
gönderilmelidir. Subkondral bölgeye kondroliz gelişmesi nedeniyle yaklaşmaktan kaçınılmalıdır. ${ }^{[26,31]}$ Vidaya bağlı komplikasyonlar; kanüle vida ve kılavuz telin eklemi perfore etmesi, epifizyal kaynamanın başarısızlığı, epifız büyümesinin durması, kaymanın devam etmesi ve implant yetmezliği gelişmesi olarak sayılabilir. Kaynama sonrası vidanın çıkarılması tartışmalıdır. ${ }^{[32]}$

\section{Kemik greft epifizyodezi}

Birçok araştırmacı tarafından açık epifizyodez olarak da tanımlanmaktadır. ${ }^{[33,34]} \mathrm{Bu}$ cerrahi teknikte femur boynundan epifizin ortasına doğru dril ve küret yardımıyla greft için bir kanal yapılır, aynı taraf iliak kanattan alınan kortikospongiyöz otogreft kanala yerleştirilir (Şekil 5). İnstabil olan FBEK'de açık redüksiyonla beraber uygulanır. Stabil FBEK'de koltuk değneğiyle basmadan mobilize edilirken instabil FBEK'de 3-6 hafta pelvipedal alçı uygulanır.

Kemik greft ile epifızyodez sonuçları tartışmalıdır. Bazı yazarlar başarılı sonuç bildirirken diğerleri yüksek AVN, kondroliz ve heterotopik osssifikasyon komplikasyonlarını bildirmişlerdir. ${ }^{[35]}$

\section{İnstabil FBEK tedavisi}

İnstabil epifiz kayması olan hastalar kalçalarında ani, şiddetli ve kırık benzeri ağrı ve basamama şikayetleri ile karşımıza çıkarlar. ${ }^{[36]}$ Prognozları zayıf olup yüksek femur başı AVN riskine sahiptirler. Halen tedavi şekli ve zamanlaması tartışmalıdır. ${ }^{[37,38]}$
Eski çalışmalarda hafif nazikçe redüksiyon ve perkütan vidalama önerilmekteydi. Yakın zamanlardaki çalışmalarda ise; açık güvenli kalça dislokasyonu ile primer anatomik redüksiyon yapılan hastalarda düşük AVN geliştiği bildirilmiştir. Fakat teknik çok zor ve ciddi deneyim gerektirmektedir. Peterson ve arkadaşlarının 91 hasta ile yaptıkları çalışmada ilk 24 saatte redüksiyon yapılanlarda $\% 7,24$ saatten sonra redüksiyon yapılanlarda \%20 AVN geliştiği gözlemlenmiştir. [39]

\section{Karşı taraf kalçanın profilaktik tedavisi}

FBEK, hastaların \%20'sinde çift taraflı olmasına rağmen profilaktik karşı kalçanın tedavisi tartışmalıdır (Şekil 6). ${ }^{[8,40]}$ Popejoy ve arkadaşlarının tek taraflı FBEK'i olan 260 hastadan oluşan çalışmasında, daha sonradan hastaların \%24'ünde karşı kalçada da epifiz kayması geliştiği bildirilmiştir. Bu hastaların çoğunluğu asemptomatiktir. Modifiye Oxford Skorunun bir komponenti olan triradiate kıkırdağın açık olduğu hastalarda, çoğunlukla karşı taraf kalçada epifiz kayması geliştiği görülmüştür. Oxford Skoru 16, 17, 18 olan hastaların \%96'sında sonradan epifiz kayması geliştiği görüldügünden bu hastalara profilaktik tedavi önerilmektedir. ${ }^{[41]}$

\section{KOMPLIKASYONLAR}

FBEK'de spesifik olarak femur başı AVN ve kondroliz gelişir. Bu komplikasyonlar ya kendiliğinden ya da tedavi ile ilşkili olarak ortaya çıkar.

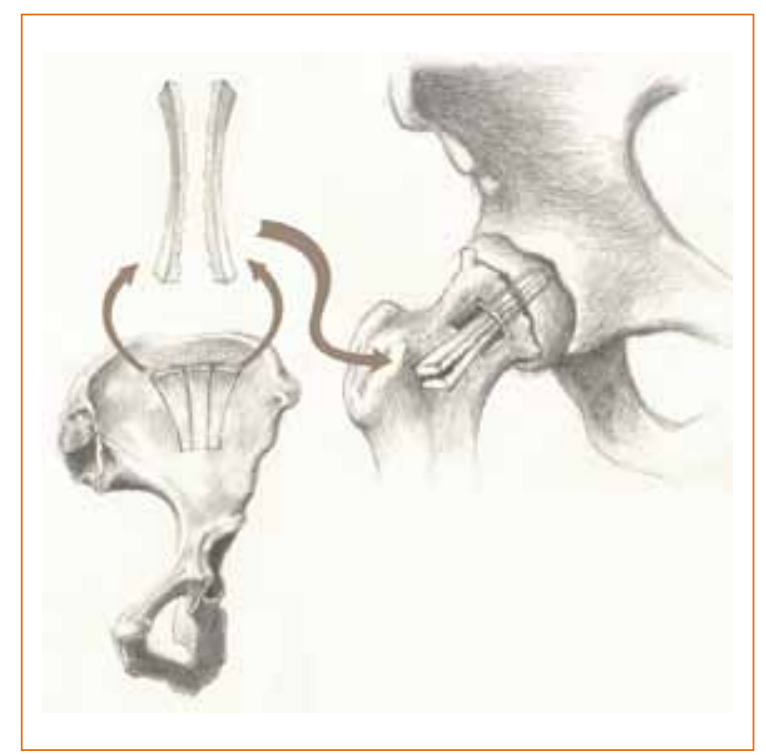

Şekil 5. Kortikospongiyöz otogreft ile epifizyodez.

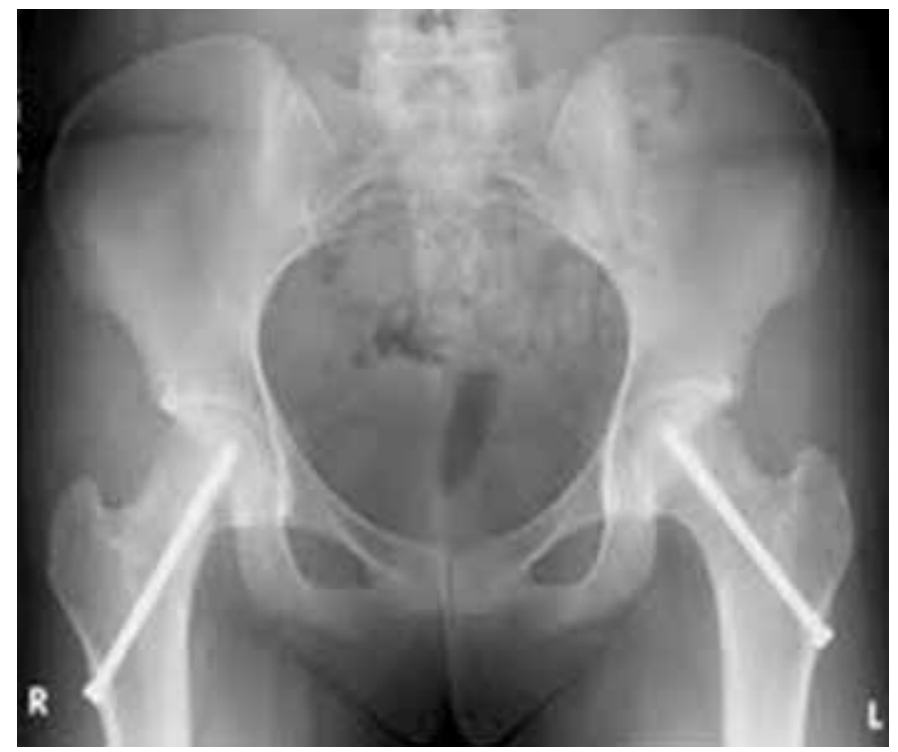

Şekil 6. Aynı seansta bilateral in situ vidalama. 


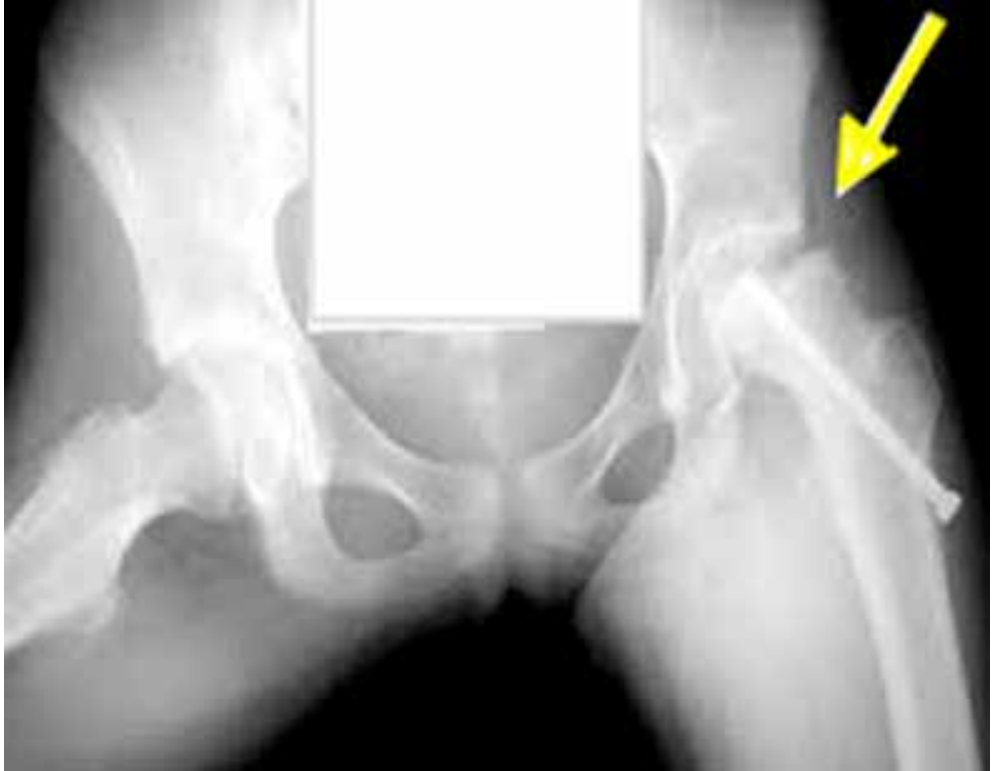

Şekil 7. Avasküler nekroz.

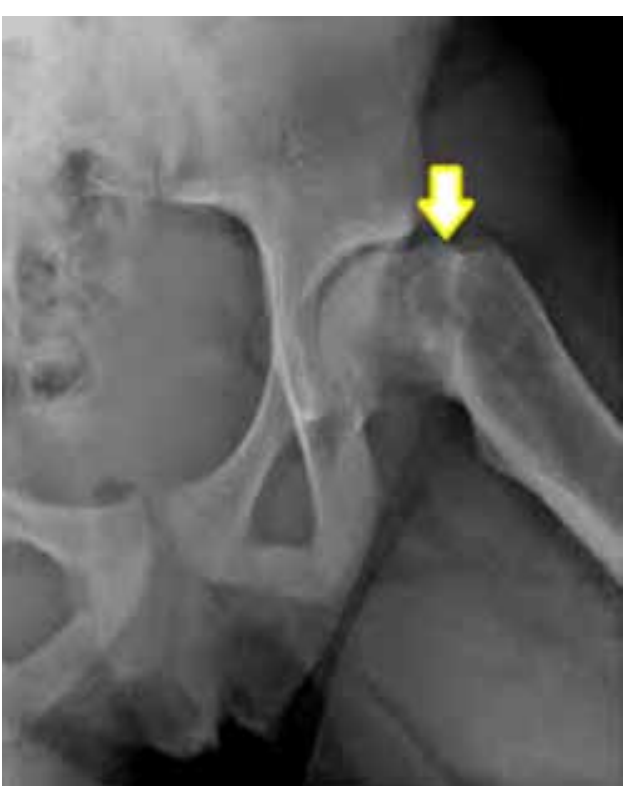

Şekil 8. FBEK zemininde sıkışma.

\section{AVN}

Femur başı AVN, FBEK'in en şiddetli komplikasyonudur. ${ }^{[10]}$ AVN'nin akut instabil epifiz kaymalarından sonra çok sık geliştiği bildirilir. Femur boyun osteotomileri ve deplase instabil femur başı epifizinin açık ya da kapalı redüksiyonu sonrasında AVN sıklığı artar. ${ }^{[22,43]}$ in situ vidalanan stabil epifiz kaymalarında ve açık epifizyodez sonrası AVN daha az görülür (Şekil 7). FBEK sonrası görülen AVN, tek bir damar hasarlanması sonrası lokalize bir bölgede görülüp kendini yenileme kapasitesi klasik Leg-Calvé-Perthes hastalığından daha azdır. Lateral epifizyel arteriyel sistem instabil FBEK'de direkt yaralanabileceği gibi, zorlayıcı redüksiyon manevraları sonrasında periostla beraber zarar görüp AVN'ye neden olabilir. Çoklu Kirchner teli uygulamasının ya da intraartiküler effüzyonun kan akımını etkileyip AVN'ye neden olabileceği ileri sürülmüştür. ${ }^{[4]}$

\section{Kondroliz}

FBEK'de kondroliz geliştiğinde, hastalar eklemde sertleşme ve süreklilik gösteren kasık ya da üst uyluk bölgesinde ağrıdan yakınırlar. Genellikle hastalar bacaklarını fleksiyon-abduksiyon-eksternal rotasyon pozisyonunda tutarlar. Yürüme ve diğer aktiviteler kalça sertliğinden dolayı kısıtlanır. Radyografide eklem boşluğu daralır. Radyolojik olarak tanı koyabilmek için eklem boşluğunun sağlam ekleme göre $\% 50$ veya daha fazla daralmış olması ya da eklem boşluğunun $3 \mathrm{~mm}$ veya daha az olması gerekir.
Kondroliz, kızlarda erkeklerden daha fazla görülür. Kondrolizin kesin nedeni bilinmez. Kondroliz, kendiliğinden gelişebileceği gibi, Kirchner teli ve vidanın penetrasyonu sonrasında da gelişebilir. Bazı yazarlar, otoimmun yanıtın kondrolize neden olduğunu ileri sürmüşlerdir. ${ }^{[44]}$

\section{Femoroasetabular sıkışma}

FBEK rezidüel deplasman ile iyileştiğinde, femoral baş-boyun offseti azalır ve proksimal metafize bölgede çıkıntı oluşur (Şekil 8). Bu metafizyal çıkıntı, femoroasetabular sıkışma, labral yırtık, eklem dejenerasyonu ve ardından dejeneratif artrite neden olur. ${ }^{[45]}$ FBEK'de, ilk defa Rab ve arkadaşları, kalçada sıkışma (impingement) kavramını tanımlamışlardır. ${ }^{[46]}$ Femur başı retroversiyonu ya da epifiz kaymasına ikincil femur boynunda gelişen deformite suçlanır. Bu anterior deformite, cam effekti oluşturup eklem kıkırdağı ve labrumda hasar yapar. Kalça ekleminin fleksiyon, adduksiyon ve internal rotasyonunda ağrının provoke olması, sıkışma için tipiktir. ${ }^{[47,48]}$ Bu deformiteler günümüzde düzeltici osteotomiler ve açık ya da artroskopik osteoplasti ile tedavi edilmektedir.

Tedavi edilmiş FBEK'i olan hastalarda deformite kalıntısı varsa; bazı birincil osteotomiler tanımlanmıştır. Bunlar femur boynunun üst ucundan (Dunn); ${ }^{[49]}$ alt kısmından intrakapsüler (Kramer) ${ }^{[50]}$ ve ekstrakapsüler (Barmada); ${ }^{\left[{ }^{11]}\right.}$ ve intertrokanterik (Imhauser ve Southwick $)^{[52]}$ osteotomilerdir (Şekil 9 a-c). 


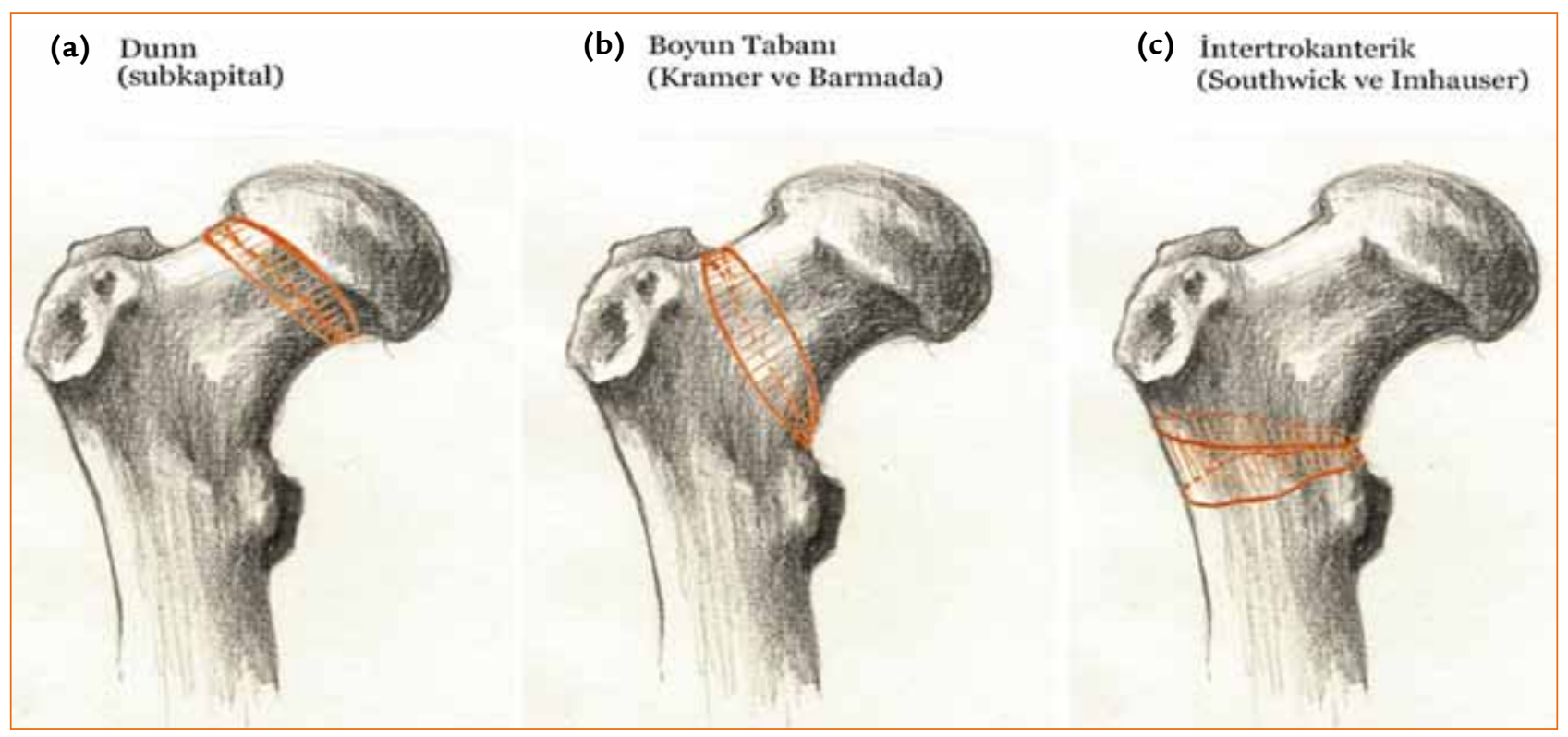

Şekil 9. a-c. Birincil osteotomiler.

\section{KAYNAKLAR}

1. Martínez-Álvarez S, Martínez-González C, Miranda Gorozarri C, Abril JC, Epeldegui T. Slipped capital femoral epiphysis. Rev Esp Cir Ortop Traumatol 2012;56(6):506-14. CrossRef

2. Shank CF, Thiel EJ, Klingele KE. Valgus slipped capital femoral epiphysis: prevalence, presentation, and treatment options. J Pediatr Orthop 2010;30(2):140-6. CrossRef

3. Riley PM, Weiner DS, Gillespie R, Weiner SD. Hazards of internal fixation in the treatment of slipped capital femoral epiphysis. J Bone Joint Surg Am 1990;72(10):1500-9.

4. Brodetti A. The blood supply of the femoral neck and head in relation to the damaging effects of nails and screws. J Bone Joint Surg Br 1960;42-B:794-801.

5. Loder RT, Aronson DD, Greenfield ML. The epidemiology of bilateral slipped capital femoral epiphysis. A study of children in Michigan. J Bone Joint Surg Am 1993;75(8):1141-7.

6. Jacobs B. Diagnosis and natural history of slipped capital femoral epiphysis. Instr Course Lect 1972;21:167-73.

7. Heyman $\mathrm{CH}$, Herndon $\mathrm{CH}$. Epiphy seodesis for early slipping of the upper femoral epiphysis. J Bone Joint Surg Am 1954;36-A(3):539-55.

8. Jerre R, Biling L, Hansson G, Karlson J, Wallin J. Bilaterality in slipped capital femoral epiphysis: importance of a reliable radiographic method. J Pediatr Orthop B 1996;5(2):80-4.

9. Riad J, Bajelidze G, Gabos PG. Bilateral slipped capital femoral epiphysis. Predictive factors for contralateral slip. J Pediatr Orthop 2007;27(4):411-4.

10. Popejoy D, Emara K, BirchJ. Prediction of contralateral slipped capital femoral epiphysis using the modified Oxford bone age score. J Pediatr Orthop 2012;32(3):290-4. CrossRef 11. Loder RT. The demographics of slipped capital femoral epiphysis. An international multicenter study. Clin Orthop Relat Res 1996;(322):8-27.

12. Muller $E$. On the deflection of the femoral neck in childhood. A new syndrome. Clin Orthop Relat Res 1966;48:7-10.
13. Southwick WO. Osteotomy through the lesser trochanter for slipped capital femoral epiphysis. J Bone Joint Surg Am 1967;49(5):807-35.

14. Aadalen RJ, Weiner DS, Hoyt W, Herndon $\mathrm{CH}$. Acute slipped capital femoral epiphysis. J Bone Joint Surg Am 1974;56(7):1473-87.

15. Mirkopulos N, Weiner DS, Askew M. The evolving slope of the proximal femoral growth plate relationship to slipped capital femoral epiphysis. J Pediatr Orthop 1988;8(3):268-73.

16. Eisenstein A, Rothschild S. Biochemical abnormalities in patients with slipped capital femoral epiphysis and chondrolysis. J Bone Joint Surg Am 1976;58(4):459-67.

17. Weiner D. Pathogenesis of slipped capital femoral epiphysis: current concepts. J Pediatr Orthop B 1996;5(2):67-73.

18. Loder RT, Starnes T, Dikos G, Aronsson DD. Demographic predictors of severity of stable slipped capital femoral epiphyses. J Bone Joint Surg Am 2006;88(1):97-105.

19. Loder RT, Hensinger RN. Slipped capital femoral epiphysis associated with renal failure osteodystrophy. J Pediatr Orthop 1997;17(2):205-11.

20. Howorth B. Slipping of the capital femoral epiphysis. Pathology. Clin Orthop Relat Res 1966;48:33-48.

21. Howoth M. Slipping of the upper femoral epiphysis. Clin Orthop 1957;10:148-73.

22. Ippolito E, Mickelson MR, Ponseti IV. A histochemical study of slipped capital femoral epiphysis. J Bone Joint Surg Am 1981;63(7):1109-13.

23. Agamanolis DP, Weiner DS, Lloyd JK. Slipped capital femoral epiphysis: a pathological study. II. An ultrastructural study of 23 cases. J Pediatr Orthop 1985;5(1):47-58.

24. Brenkel IJ, Dias JJ, Iqbal SJ, Gregg PJ. Thyroid hormone levels in patients with slipped capital femoral epiphysis. J Pediatr Orthop 1988;8(1):22-5. 
25. Nicolai RD, Grasemann H, Oberste-Berghaus C, Hövel M, Hauffa BP. Serum insulin-like growth factors IGF-I and IGFBP-3 in children with slipped capital femoral epiphysis. J Pediatr Orthop B 1999;8(2):103-6.

26. Jahss SA. Slipping of the upper femoral epiphysis: treatment in the preslipping stage. J Bone Joint Surg 1933;15:477.

27. Kumm DA, Schmidt J, Eisenburger SH, Rütt J, Hackenbroch $\mathrm{MH}$. Prophylactic dynamic screw fixation of the asymptomatic hip in slipped capital femoral epiphysis. J Pediatr Orthop 1996;16(2):249-53.

28. Klein A, Joplin RJ, Reidy JA,Hanelin J. Roentgenographic features of slipped capital femoral epiphysis. Am J Roentgenol Radium Ther 1951;66(3):361-74.

29. Guzzanti V, Falciglia F. Slipped capital femoral epiphysis: comparison of a roentgenographic method and computed tomography in determining slip severity. J Pediatr Orthop 1991;11(1):6-12.

30. Kallio PE, Paterson DC, Foster BK, Lequesne GW. Classification in slipped capital femoral epiphysis. Sonographic assessment of stability and remodeling. Clin Orthop Relat Res 1993;(294):196-203.

31. Lalaji A, Umans $H$, Schneider R, Mintz D, Liebling MS, Haramati N. MRI features of confirmed "pre-slip" capital femoral epiphysis: a report of two cases. Skeletal Radiol 2002;31(6):362-5.

32. Kulick RG, Denton JR. A retrospective study of 125 cases of slipped capital femoral epiphysis. Clin Orthop Relat Res 1982;(162):87-90.

33. Bellemans J, Fabry G, Molenaers G, Lammens J, Moens P. Pin removal after in-situ pinning for slipped capital femoral epiphysis. Acta Orthop Belg 1994;60(2):170-2.

34. Aronson DD, Carlson WE. Slipped capital femoral epiphysis. A prospective study of fixation with a single screw. J Bone Joint Surg Am 1992;74(6):810-9.

35. Ferguson A, Howorth M. Slipping of the upper femoral epiphysis. JAMA 1931;97:1867.

36. Adamczyk MJ, Weiner DS, Hawk D. A 50-year experience with bone graft epiphysiodesis in the treatment of slipped capital femoral epiphysis. J Pediatr Orthop 2003;23(5):578-83.

37. Loder RT, Richards BS, Shapiro PS, Reznick LR, Aronson DD. Acute slipped capital femoral epiphysis: the importance of physeal stability. J Bone Joint Surg Am 1993;75(8):1134-40.

38. Bellemans J, Fabry G, Molenaers G, Lammens J, Moens P. Slipped capital femoral epiphysis: a long-term follow-up, with special emphasis on the capacities for remodeling. J Pediatr Orthop B 1996;5(3):151-7.

39. Crandall DG, Gabriel KR, Akbarnia BA. Second operation for slipped capital femoral epiphysis: pin removal. J Pediatr Orthop 1992;12(4):434-7.
40. Peterson MD, Weiner DS, Green NE, Terry CL. Acute slipped capital femoral epiphysis: the value and safety of urgent manipulative reduction.J Pediatr Orthop 1997;17(5):648-54.

41. Jerre R, Billing L, Hansson G, Wallin J. The contralateral hip in patients primarily treated for unilateral slipped upper femoral epiphysis. Long-term follow-up of 61 hips. J Bone Joint Surg Br 1994;76(4):563-7.

42. Clarke HJ, Wilkinson JA. Surgical treatment for severe slipping of the upper femoral epiphysis. J Bone Joint Surg $\mathrm{Br}$ 1990;72(5):854-8.

43. Gage JR, Sundberg AB, Nolan DR, Sletten RG, Winter RB. Complications after cuneiform osteotomy for moderately or severely slipped capital femoral epiphysis. J Bone Joint Surg Am 1978;60(2):157-65.

44. Stambough JL, Davidson RS, Ellis RD, Gregg JR. Slipped capital femoral epiphysis: an analysis of 80 patients as to pin placement and number. J Pediatr Orthop 1986;6(3):265-73.

45. Herring JA. Slipped capital femoral epiphysis. In: Herring JA, editor. Tachdjian's Pediatric Orthopaedics: from the Texas Scottish Rite Hospital for Children, 5th ed. Philadelphia: Elsevier; 2014. p.645.

46. Loder RT, Mehbod AA, Meyer C, Meisterling M. Acetabular depth and race in young adults: a potential explanation of the differences in the prevalence of slipped capital femoral epiphysis between different racial groups? J Pediatr Orthop 2003;23(6):699-702.

47. Millis MB, Novais EN. In situ fixation for slipped capital femoral epiphysis: perspectives in 2011. J Bone Joint Surg Am 2011;93 Suppl 2:46-51. CrossRef

48. Beck M, Leuning M, Parvizi J, Boutier V, Wyss D, Ganz R. Anterior femoroacetabular impingement: part II. Midterm results of surgical treatment. Clin Orthop Relat Res 2004;(418):67-73.

49. Dunn DM, AngelJC. Replacement of the femoral head by open operation in severe adolescent slipping of the upper femoral epiphysis. J Bone Joint Surg Br 1978;60-B(3):394-403.

50. Kramer WG, Craig WA, Noel S. Compensating osteotomy at the base of the femoral neck for slipped capital femoral epiphysis. J Bone Joint Surg Am 1976;58(6):796-800.

51. Barmada R, Bruch RF, Gimbel JS, Ray RD. Base of the neck extracapsular osteotomy for correction of deformity in slipped capital femoral epiphysis. Clin Orthop Relat Res 1978;(132):98-101.

52. Southwick WO. Osteotomy through the lesser trochanter for slipped capital femoral epiphysis. J Bone Joint Surg Am 1967;49(5):807-35. 